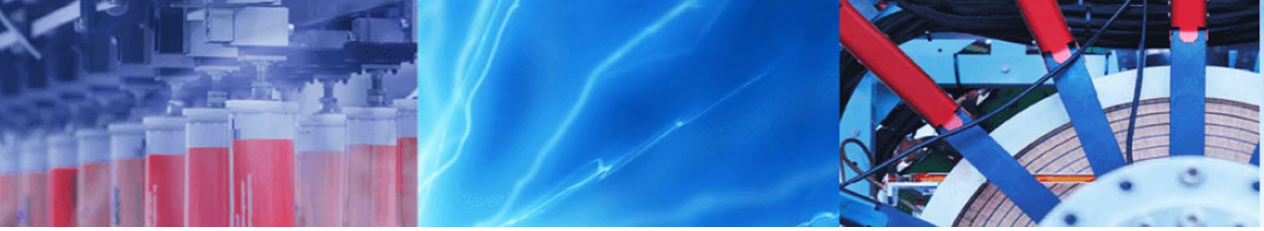

Research Article

\title{
Acetylation of alcohols, phenols and amines using waste plant extract
}

\author{
Rituparna Chutia ${ }^{1} \cdot$ Bolin Chetia $^{1}$
}

Received: 26 February 2020 / Accepted: 17 August 2020 / Published online: 26 August 2020

(c) Springer Nature Switzerland AG 2020

\begin{abstract}
The acetylation of alcohols, phenols and amines using water extract of waste plant extract of rice straw ash and seed husk of Vigna mungo ash at room temperature is reported here. The easy availability of plants, high yields, mild reaction conditions, cost effectiveness of the catalyst proved to be an excellent and green protocol for the acetylation reaction.
\end{abstract}

Keywords Acetylation · Green · Waste materials · Vigna mungo · Rice straw · Gram scale synthesis

\section{Introduction}

Acetylation reactions have been an important transformation [1] in organic synthesis. These reactions have been used as protective group reactions in agricultural and pharmaceutical industries [2-4]. The transformation has been usually carried out with acetic acid or acetic anhydride in presence of acidic or basic conditions. Amines with carboxylic acid derivatives such as lachrymatory acetyl chloride, acids or esters undergo $\mathrm{N}$-acetylation reactions.

Several methods have been cited in literature for acetylation reaction of alcohols, phenols and amines using different acid or base (Table 1), but they have one or more disadvantages such as the use of harsh reaction conditions, longer reaction time, use of expensive catalyst etc.

Recently reported methods includes the use of metal triflates such as $\mathrm{Ce}(\mathrm{OTf})_{3}$ [11], $\mathrm{Sc}(\mathrm{OTf})_{3}$ [12], $\mathrm{Cu}(\mathrm{OTf})_{2}$ [13], indium triflate [14], Gadolinium triflate [15], $\mathrm{Al}(\mathrm{OTf})_{3}$ [16]; metal halides such as $\mathrm{TaCl}_{5}[17], \mathrm{InCl}_{3}[18]$, and $\mathrm{ZrOCl}_{2} \cdot 8 \mathrm{H}_{2} \mathrm{O}$ [19]; and solid acid catalysts such as heteropoly acids [20], $\mathrm{Mg}\left(\mathrm{NTf}_{2}\right)_{2}$ [21], aluminum-supported $\mathrm{MoO}_{3}$ [22], $\mathrm{BiFeO}_{3}$ [23], cation-exchanged montmorillonite K-10 clay [24], phosphomolybdic acid [25], sulfamic acid [26], $\mathrm{NaHSO}_{4}$.
$\mathrm{SiO}_{2}$ [27], polystyrene-bound heterogeneous cobalt(II) salen [28], and [TMBSA] $\left[\mathrm{HSO}_{4}\right]$ ionic liquid [29] for acetylation reactions. The preparation of these catalyst normally require harsh reaction conditions, use of toxic chemicals and poor yields are normally obtained.

All these harsh reaction conditions can likely be overcome by using eco-friendly green catalyst for the acetylation reactions. Green chemistry aims at the use of biodegradable, eco-friendly catalyst and the use of plant extracts as catalyst and solvent enhance this application. Plants as green solvents and catalyst offers shorter reaction time, use of non-toxic solvent making an overall extraction process more environment friendly [30]. Thus, owing to the principles of Green Chemistry [31] researchers nowadays are focusing their interest on the use of agricultural waste residues in chemical reactions. These waste plant extract are normally basic in nature, and as cited in literature acetylation reactions is efficiently performed in the presence of base as catalyst. Thus, citing to all the advantages of the plant extracts and considering the increasing pressure from environmentalist we tried to use the waste plant extract of Vigna mungo and rice straw as a catalyst in the acetylation reaction.

Electronic supplementary material The online version of this article (https://doi.org/10.1007/s42452-020-03353-2) contains supplementary material, which is available to authorized users.

Bolin Chetia, bolinchetia@dibru.ac.in | 'Department of Chemistry, Dibrugarh University, Dibrugarh, Assam 786004, India. 
Table 1 Few Acetylation reactions using different acids/bases

\begin{tabular}{|c|c|c|c|c|c|}
\hline Entry & Substrates & Reaction condition, Time & Acid/Base & Catalyst & Refs. \\
\hline 1 & Alcohol, Phenols & $\mathrm{Ac}_{2} \mathrm{O}$, Ethyl acetate, $48 \mathrm{~h}$ & $\mathrm{NaHCO}_{3}(2 \mathrm{eq})$ & - & [5] \\
\hline 2 & Alcohols & $\mathrm{Ac}_{2} \mathrm{O}, \mathrm{CH}_{2} \mathrm{Cl}_{2}, 3 \mathrm{~h}$ & DMAP & Tributylphosphine & [6] \\
\hline 3 & Alcohols & $\mathrm{Ac}_{2} \mathrm{O}, 10 \mathrm{~h}$ & $\mathrm{~N}, \mathrm{~N}$-dimethyl-4-pyridinamine & - & [7] \\
\hline 4 & Amines & Toluene, $110^{\circ} \mathrm{C}, 22 \mathrm{~h}$ & Carboxylic acids & $\mathrm{ZrCp}_{2} \mathrm{Cl}_{2}$ & [8] \\
\hline 5 & Amines & Toluene/fluorobenzene, $22 \mathrm{~h}$ & - & Aminoboronic Acids & [9] \\
\hline 6 & Amines & EtOAc, $70^{\circ} \mathrm{C}, 24 \mathrm{~h}$ & Pivalic or acetic acid & - & [10] \\
\hline
\end{tabular}

In many countries, rice straw is an abundant lignocellulose by-product from rice (Oryza sativa) production in farming. Similarly, during milling of black gram (Vigna mungo) into dhal, husk (seed coat) is a waste by-product that constitutes about $9 \%$ of the grain. These large quantities of agricultural residues are reserved only in a minor amount for animal feed, paper industry, household fuel etc. A huge quantity is wasted and burnt or disposed as it is no use.

Rice straw mainly contain lignocelluloses as the main component which is a compact structure of cellulose (28-36\%) and hemicelluloses (23-28\%) in close association with lignin (12-16\%) [32]. Black gram lentil (Vigna mungo L.) is a rich source of fibre, protein, several vitamins and essential minerals such as calcium and iron [33]. Prasada Rao et al. found that the husk of Vigna mungo had the highest dietary fibre content (78.5\%) [34] and carotenoids. Similar to total polyphenol content, anthocyanin content was also found to be the highest in husk fraction ( $87 \mathrm{mg} / 100 \mathrm{~g}$ ). Due to the burning or disposal of these agricultural residues, the valuable components in them are wasted and it causes pollution in the atmosphere which is a threat to the environment [35].

This paper thus reports the application of waste plant extract of Vigna mungo and rice straw as an excellent catalyst for the acetylation of various alcohols, phenols and amines. The easy availability of these waste residues and eco-friendly nature also added as an advantage for its utilization as a green catalyst. The high catalytic activity may be due to the basic nature of the waste plant extract and the presence of various fibres, proteins, polyphenols, lignins, cellulose and vitamins in these extracts enhance them to proceed as an efficient catalyst.

\section{Experimental}

\subsection{Preparation of catalyst}

Vigna mungo (black gram) and rice straw were collected from the nearby area of Dibrugarh University, Dibrugarh, Assam, India. They were air dried and the husk of Vigna mungo was removed, and the rice straw was separated. It was then washed with deionized water and air dried. $4 \mathrm{~g}$ of both dry Vigna mungo husk and rice straw were taken separately and burnt to ashes in a furnace and $3.5 \mathrm{~g}$ of ash was obtained. This was then warmed at $50^{\circ} \mathrm{C}$ in $100 \mathrm{~mL}$ deionised water separately for $15 \mathrm{~min}$ where almost all the ashes got dissolved, and filtered with whatmann No. 1 filter paper. The filtrate obtained is thus named as Water Extract of Vigna mungo seed husk (WEVMS) and Water extract of rice straw ashes (WERSA) (Fig. 1). Both the extracts were then used as a catalyst for the acetylation reaction of various alcohols, phenols and amines.

\section{General procedure for acetylation reaction}

To a mixture of substrate $(0.537 \mathrm{mmol})$ and acetic anhydride ( 1 eq), $70 \mu \mathrm{L}$ of the WERSA/ $40 \mu \mathrm{L}$ of WEVMS was added and stirred at room temperature for appropriate time. The progress of the reaction was monitored by TLC. The product was extracted with ethyl acetate, dried over anhydrous $\mathrm{Na}_{2} \mathrm{SO}_{4}$ and evaporated. The reaction completed in in very short time without the formation of any side products (Scheme 1). The characterization of the products was done by ${ }^{1} \mathrm{H}$ NMR and ${ }^{13} \mathrm{C}$ NMR. The reaction was initially carried out using aniline and acetic anhydride as a model reaction by using WERSA/WEVMS as a catalyst.

\section{Result and discussion}

Literature cited the presence of twelve different types of flavonoids [36] i.e. two leucoanthocyanins, two glycoflavones, three anthocyanins and five flavonol glycosides in the seed coats of Vigna mungo. In another study the seed coat was found to contain the saponins of soyasaponins I, II and V [37].

The EDX analysis of the both dry Vigna mungo seed husk and rice straw ashes were performed and are shown in Fig. 2. The report reveals a very high distribution of the oxides of $\mathrm{K}, \mathrm{Si}$, Ca in Vigna mungo seed husk; and the 


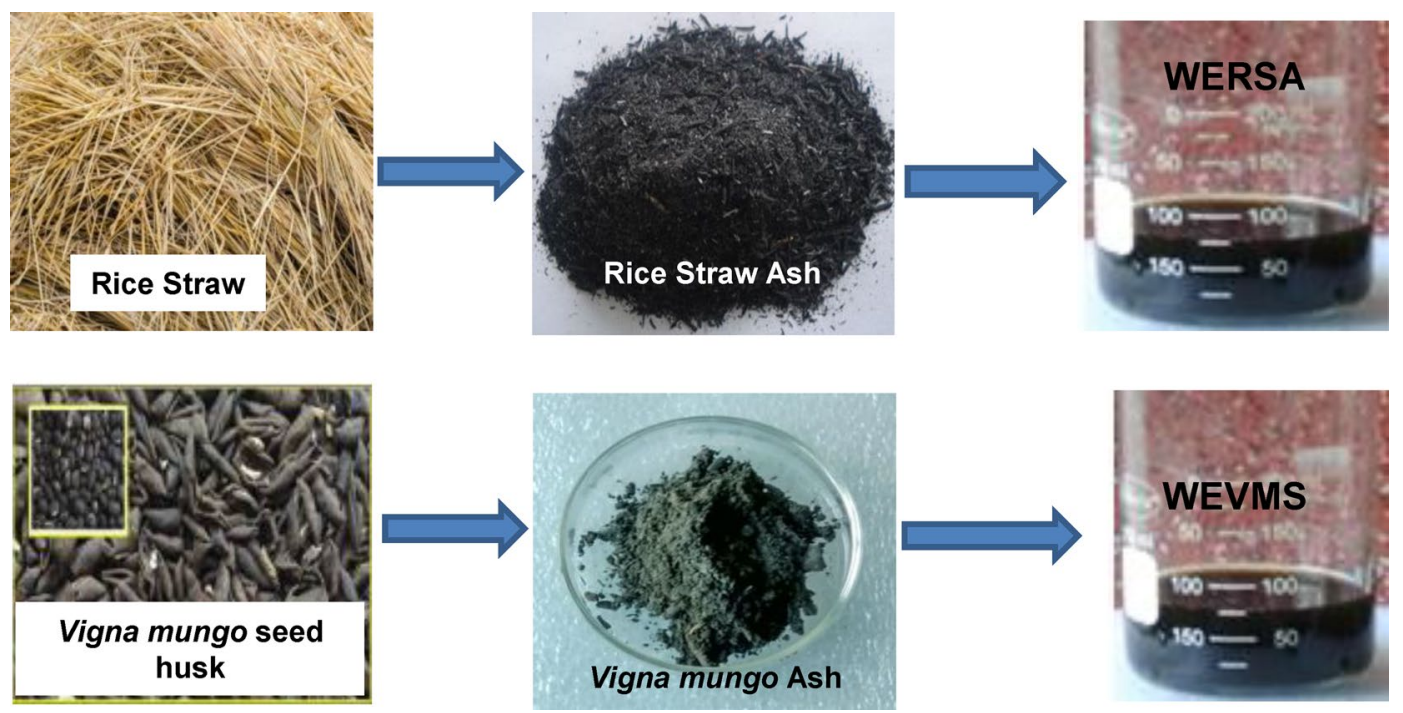

Fig. 1 Preparation of the catalyst

Scheme 1 General scheme for acetylation reaction

Fig. 2 a EDX spectrum of the dry ashes of Vigna mungo seed husk, $\mathbf{b}$ EDX spectrum of the dry ashes of Rice Straw
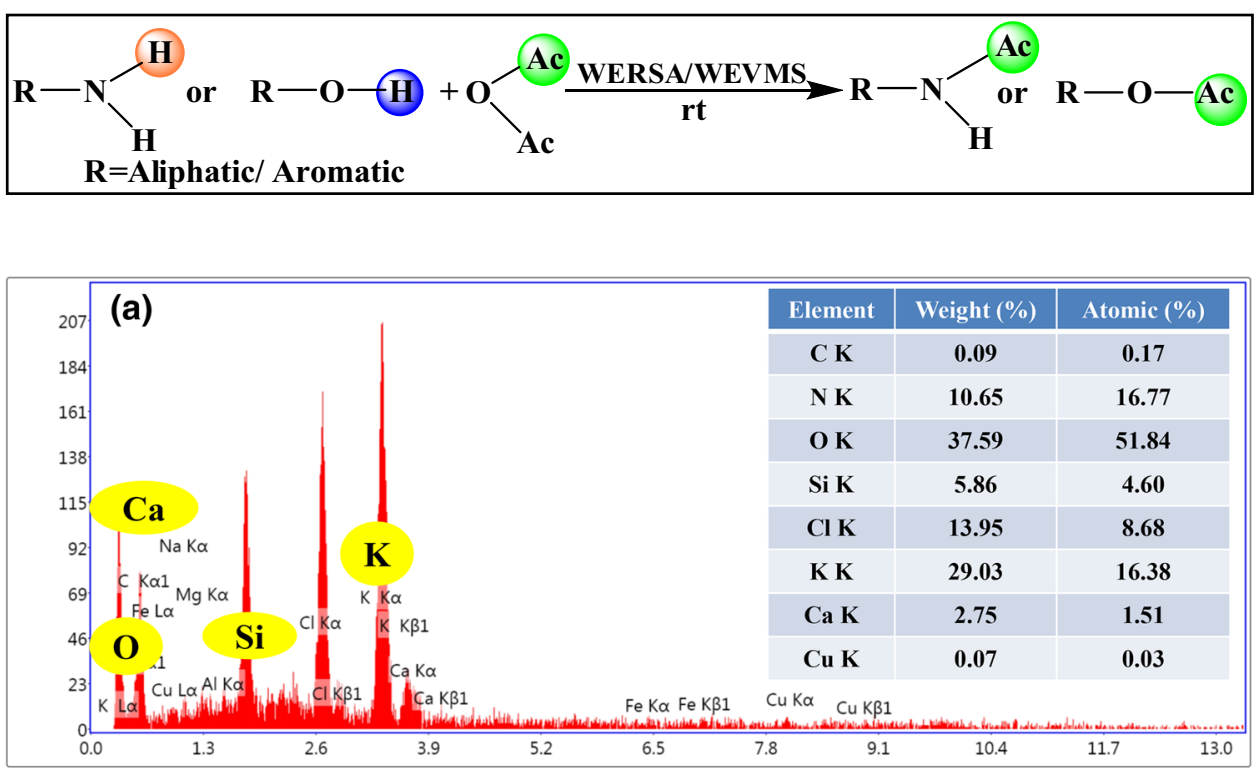

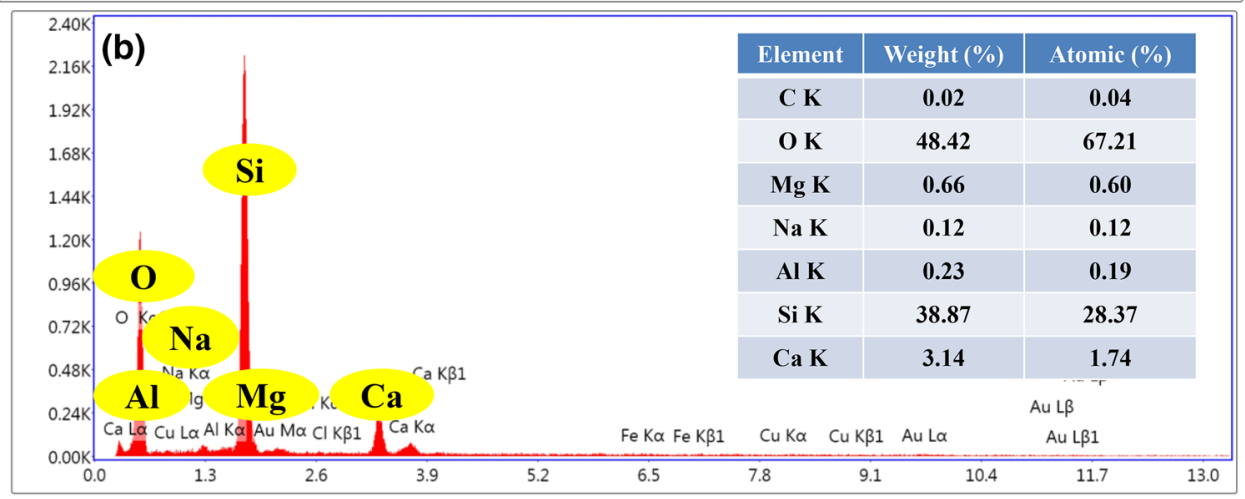




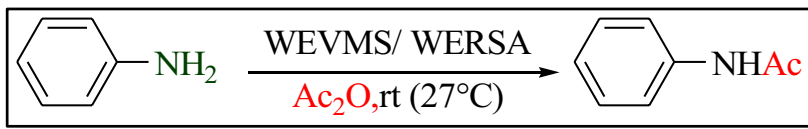

Scheme 2 Model reaction used for optimization

presence of $\mathrm{Na}, \mathrm{Mg}, \mathrm{Al}, \mathrm{Si}, \mathrm{Ca}$ in rice straw ashes. The $\mathrm{pH}$ measurement of both the extract was tested using Digital $\mathrm{pH}$ meter model 111/101 and found to be 8.84 in WEVMS and 9.61 in WERSA. This proved the basic nature of the WEVMS and WERSA.

The effectiveness of the WEVMS/WERSA was then explored in the acetylation reactions of various alcohols, phenols and amines. We initially, optimized our reaction condition by performing the acetylation of aniline as the model substrate (Scheme 2). The effects of different amounts of the WEVMS/WERSA were monitored for different intervals of time (Table 2). The best result was obtained when $40 \mu \mathrm{L}$ of WEVMS (Table 2, entry 5), and 70 $\mu \mathrm{L}$ of WERSA (Table 2 , entry 6 ), were used respectively. However, without the use of extract the reaction did not proceed up to $240 \mathrm{~min}$. Thus this seems to be the fastest, economic and green protocol for the acetylation reaction. On increasing the amount of WEVMS to $50 \mu \mathrm{L}$ no change in the yield of the product was obtained.

The reaction was also explored by the influence of different bases on the model reaction of aniline and acetic anhydride (Table 3). As the pH of both WERSA and WEVMS was found to be basic, so we prepared some base solutions in the same $\mathrm{pH}$ range of 9.2 for optimization. Surprisingly, it was found that the addition of our catalyst led to the immediate formation of the product, while the bases required more time.

We further optimized our reaction using different amounts of acetic anhydride (Table 4 ) on the model reaction. It was observed that by using 0.5 equivalent of $\mathrm{Ac}_{2} \mathrm{O}$ (Table 4, entry 5) nearly $60 \%$ product yield was found, this might be because of the longer reaction time for the
Table 3 Effects of the amount of different bases in the acetylation on the model reaction

\begin{tabular}{llll}
\hline Entry & Base & Amount $(\mu \mathrm{L})$ & Time $(\mathrm{min})$ \\
\hline $1^{\mathrm{a}}$ & $\mathrm{KOH}$ & 400 & 25 \\
$2^{\mathrm{a}}$ & $\mathrm{NaOH}$ & 40 & 15 \\
$3^{\mathrm{a}}$ & $\mathrm{K}_{2} \mathrm{CO}_{3}$ & 400 & 45 \\
4 & WERSA & 70 & $<1 \mathrm{~min}$ \\
5 & WEVMS & 40 & $<1 \mathrm{~min}$ \\
\hline
\end{tabular}

Reaction Conditions: Aniline $(0.537 \mathrm{mmol}), \mathrm{Ac}_{2} \mathrm{O}(1 \mathrm{eq})$, room temperature

${ }^{\mathrm{a}}$ Base: $0.000016 \mathrm{M}$

Table 4 Optimization of acetic anhydride on the model reaction

\begin{tabular}{|c|c|c|c|}
\hline Entry & $\mathrm{Ac}_{2} \mathrm{O}$ (Equiv.) & Time (min) & Yield $^{\mathrm{a}}(\%)$ \\
\hline 1 & 0 & 240 & No produc \\
\hline 2 & 0.2 & 60 & Trace \\
\hline 3 & 0.3 & 40 & 30 \\
\hline 4 & 0.4 & 40 & 45 \\
\hline 5 & 0.5 & 20 & 60 \\
\hline 6 & 1 & $<1 \mathrm{~min}$ & 98 \\
\hline 7 & 1.1 & $40 \mathrm{~s}$ & 98 \\
\hline 8 & 1.2 & $1 \mathrm{~min}$ & 96 \\
\hline 9 & 2.0 & $5 \mathrm{~min}$ & 96 \\
\hline
\end{tabular}

Reaction Conditions: Aniline $(0.537 \mathrm{mmol})$ at room temperature a Isolated Yields

product formation. The reaction progressed immediately after the addition of the extract by using 1 equivalent of acetic anhydride (Table 4, entry 6).

\subsection{Acetylation of different substrates using extracts}

The above optimization condition was explored using 20 different substrates of alcohols, phenols and amines
Table 2 Effects of the amount of WEVMS in the acetylation on the model reaction ${ }^{\mathrm{a}}$

\begin{tabular}{|c|c|c|c|c|c|c|}
\hline \multirow[t]{2}{*}{ Entry } & \multicolumn{3}{|l|}{ WEVMS } & \multicolumn{3}{|l|}{ WERSA } \\
\hline & Amount $(\mu \mathrm{L})$ & Time (min) & Yield (\%) & Amount $(\mu \mathrm{L})$ & Time (min) & Yield $(\%)^{b}$ \\
\hline $1^{c}$ & $\mathbf{0}$ & 240 & No product & 0 & 240 & No product \\
\hline 2 & 10 & 60 & Trace & 20 & 60 & 80 \\
\hline 3 & 20 & 60 & 80 & 40 & 60 & 90 \\
\hline 4 & 30 & 10 & 90 & 50 & 15 & 98 \\
\hline 5 & 40 & $<1$ & 98 & 60 & 10 & 98 \\
\hline 6 & 50 & $<1$ & 98 & 70 & $<1$ & 98 \\
\hline
\end{tabular}

${ }^{a}$ Reaction Conditions: Aniline $(0.537 \mathrm{mmol}), \mathrm{Ac}_{2} \mathrm{O}(1 \mathrm{eq})$, room temperature

${ }^{\mathrm{b}}$ Isolated yields

${ }^{\mathrm{c}}$ Reactions carried out without Extract 
Table 5 Substrate scope variation of the acetylation reaction with $\mathrm{Ac}_{2} \mathrm{O}$ under solvent free conditions in the presence of $\mathrm{Extract}^{\mathrm{a}}$

\begin{tabular}{|c|c|c|c|c|}
\hline S. No & Substrate & Product & Time (min) & Yield $^{\mathrm{b}} \%$ \\
\hline 1 & & & $<1$ & 98 \\
\hline 2 & & & 5 & 98 \\
\hline 3 & & & 5 & 95 \\
\hline & & & 5 & 95 \\
\hline & & & 5 & 96 \\
\hline 6 & & & 5 & 97 \\
\hline & & & 10 & 95 \\
\hline 8 & & & 20 & 95 \\
\hline & & & 60 & 90 \\
\hline 10 & & & 50 & 75 \\
\hline & & & 50 & 75 \\
\hline & & & 45 & $80^{\mathrm{c}}$ \\
\hline 13 & & & & \\
\hline 14 & & & 60 & 90 \\
\hline 15 & & & 30 & 95 \\
\hline 16 & & & 30 & 90 \\
\hline 17 & & & 30 & 92 \\
\hline 18 & & & 60 & 95 \\
\hline 19 & & & 30 & 93 \\
\hline 20 & & & 30 & $80^{\mathrm{c}}$ \\
\hline
\end{tabular}

${ }^{a}$ Reaction conditions: alcohols/phenols/anilines $(0.537 \mathrm{mmol})$, WERSA(70 $\left.\mu \mathrm{L}\right) /$ WEVMS $(40 \mu \mathrm{L})$, acetic anhydride (1 eq)

b Isolated Yield

${ }^{\text {Ref. [38, 39] }}$ 


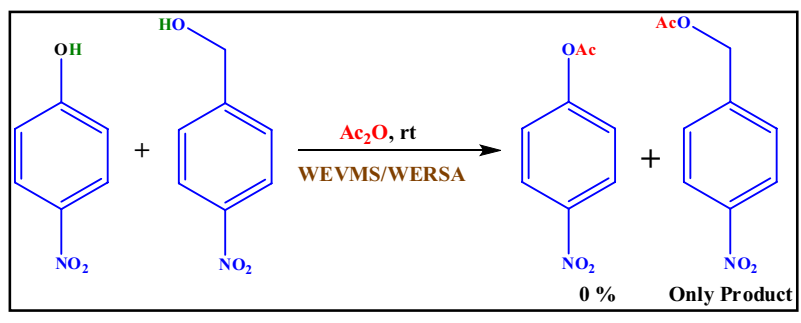

Scheme 3 Chemoselectivity in presence of extract

(Table 5). Excellent yields have been obtained with the aniline derivatives compared to alcohols and phenols. The chemoselectivity was however not observed with two different functional groups such as $-\mathrm{NH},-\mathrm{OH}$ and -SH (entries $12,13,20)[38,39]$. We were surprised to find that by using 1 eq of $\mathrm{Ac}_{2} \mathrm{O}$ for $0.537 \mathrm{mmol}$ of the substrate (entries $12,13,20$ ) diacetylated products were obtained with isolated yields, however the reaction required longer reaction time compared to the acetylated products. This might be because the acetic acid formed in the reaction as a by-product would act as acetylating agent for the diacetylation.

The chemoselectivity was evaluated using a mixture of substituted benzyl alcohol and phenol. An equimolar mixture of 4-nitro benzyl alcohol and 4-nitro phenol was reacted with acetic anhydride in presence of extract as catalyst. The result of this reaction revealed that it proceeded with absolute chemoselectivity towards 4-nitro benzyl alcohol (Scheme 3). The absolute chemoselectivity of benzyl alcohol might be because acetylation of substituted phenols required longer reaction time compared to benzyl alcohols as shown in Table 5.

The multi-gram scale synthesis of aniline was also performed to demonstrate the practicality of this approach (Scheme 4). The reaction proceeded smoothly with only $100 \mu \mathrm{L}$ of the extract and $98 \%$ of the product was obtained.

We further compared the efficiency of the WEVMS/ WERSA as catalyst with previously reported catalyst for the acetylation reaction of aniline and acetic anhydride as the model substrate (Table 6). The previously reported catalyst suffered one or more disadvantages compared to our green and ecofriendly superior catalyst.

\section{Conclusion}

The present work describes an environmentally-friendly, economic, excellent protocol for the acetylation reaction using waste material of plants for the first time showing immediate formation of product for the acetylation of aniline. Subsequently, high yields in short reaction times were achieved for various alcohols, phenols and amines without the need of an expensive catalyst. Moreover the chemo selectivity of the catalyst has also enhanced its application. The easy availability of the catalyst, cost effectiveness, less reaction time, high yield products, mild reaction
Scheme 4 Multi-gram scale synthesis of N-phenylacetamide

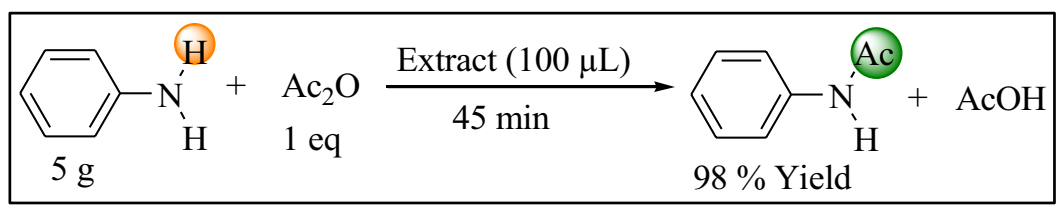

Table 6 Comparison efficiency of WEVMS/WERSA with some reported catalysts for the acetylation reactions of aniline

\begin{tabular}{llllll}
\hline Entry & Reaction conditions & Time & Amount of catalyst & Yield (\%) & Refs. \\
\hline 1 & CDI DMAc & $1 \mathrm{~h}$ & $2 \mathrm{~mol}$ eqiv & 85 & {$[40]$} \\
2 & Zinc Acetate (Microwave) & $20 \mathrm{~min}$ & $0.045 \mathrm{mmol}$ & 91 & {$[41]$} \\
3 & $\mathrm{RHA} \mathrm{TiO}_{2}$ & $9 \mathrm{~h}$ & $20 \mathrm{~mol}$ & 93 & {$[42]$} \\
4 & $\mathrm{Fe}_{3} \mathrm{O}_{4} @ \mathrm{PDA}-\mathrm{SO}_{3} \mathrm{H}$ & $30 \mathrm{~min}$ & $2 \mathrm{~mol}$ & 96 & {$[43]$} \\
5 & Zeolite H-FER & $2 \mathrm{~h}$ & $150 \mathrm{mg}$ & 99 & {$[44]$} \\
6 & WEVMS/WERSA & $<1 \mathrm{~min}$ & $40 \mu \mathrm{L} / 70 \mu \mathrm{L}$ & 98 & This Work \\
\hline
\end{tabular}


conditions proved to be a green and excellent protocol for the acetylation reaction.

Acknowledgements $B C$ gratefully acknowledges DST-SERB (project No. SB/FT/CS-161/2012) for financial assistance, UGC-SAP and SAIF, NEHU Shillong for spectral data.

\section{Compliance with ethical standards}

Conflict of interest On behalf of all authors, the corresponding author states that there is no conflict of interest.

\section{References}

1. Greene TW, Wuts PGM (1999) Protective groups in organic synthesis, 3rd edn. Wiley, New York

2. Scozzafava A, Owa T, Mastrolorenzo A, Supuran CT (2003) Anticancer and antiviral sulfonamides. Curr Med Chem 10:925-953. https://doi.org/10.2174/0929867033457647

3. Carey JS, Laffan D, Thomson C, Williams MT (2006) Analysis of the reactions used for the preparation of drug candidate molecules. Org Biomol Chem 4:2337-2347. https://doi.org/10.1039/B6024 $13 \mathrm{~K}$

4. Abbate F, Supuran CT, Scozzafava A, Orioli P, Stubbs MT, Klebe $G$ (2002) Nonaromatic sulfonamide group as an ideal anchor for potent human carbonic anhydrase inhibitors: role of hydrogenbonding networks in ligand binding and drug design. J Med Chem 45:3583. https://doi.org/10.1021/jm011131t

5. Lugemwa FN, Shaikh K, Hochstedt E (2013) Facile and efficient acetylation of primary alcohols and phenols with acetic anhydride catalyzed by dried sodium bicarbonate. Catalysts 3:954965. https://doi.org/10.3390/catal3040954

6. Vedejs E, Bennett NS, Conn LM, Diver ST, Gingras M, Lin S, Oliver PA, Peterson MJ (1993) Tributylphosphine-catalyzed acylations of alcohols: scope and related reactions. J Org Chem 58:72867288. https://doi.org/10.1021/jo00077a064

7. Steglich DW, Höfle G (1969) N,N-dimethyl-4-pyridinamine, a very effective acylation catalyst. Angew Chem Int Ed 8:981. https:// doi.org/10.1002/anie.196909811

8. Allen CL, Chhatwal R, Williams JMJ (2012) Direct amide formation from unactivated carboxylic acids and amines. Chem Commun 48:666-668. https://doi.org/10.1039/C1CC15210F

9. Georgiou I, llyashenko G, Whiting A (2009) Synthesis of aminoboronic acids and their applications in bifunctional catalysis. Acc Chem Res 42:756-768. https://doi.org/10.1021/ar800262v

10. Tomoki Y, Shimpei K, Kenya N (2017) Chemoselective N-acetylation of primary aliphatic amines promoted by pivalic or acetic acid using ethyl acetate as an acetyl donor. Tetrahedron Lett 58:1181-1184. https://doi.org/10.1016/j.tetlet.2017.02.015

11. Bartoli G, Dalpozzo R, De Nino A, Maiuolo L, Bucci P, Rende A, $\mathrm{Cz} B$ (2004) Per- O -acetylation of sugars catalyzed by $\mathrm{Ce}(\mathrm{OTf})_{3}$. Green Chem 3:191-192. https://doi.org/10.1039/B400920G

12. Lee JC, Tai CA, Hung SC (2002) Sc(OTf) ${ }_{3}$-catalyzed acetolysis of 1,6-anhydro- $\beta$-hexopyranoses and solvent-free per-acetylation of hexoses. Tetrahedron Lett 43:851-855. https://doi. org/10.1016/S0040-4039(01)02253-5

13. Tai CA, Kulkarni SS, Hung SC (2003) Facile Cu(OTf) $)_{2}$-catalyzed preparation of per-O-acetylated hexopyranoses with stoichiometric acetic anhydride and sequential one-pot anomeric substitution to thioglycosides under solvent-free conditions. J Org Chem 68:8719-8722. https://doi.org/10.1021/jo030073b
14. Bizier NP, Atkins SR, Helland LC, Colvin SF, Twitchell JR, Cloninger MJ (2008) Indium triflate catalysed peracetylation of carbohydrates. Carbohydr Res 343:1814-1818. https://doi.org/10.1016/j. carres.2008.04.009

15. Alleti R, Oh WS, Perambuduru M, Afrasiabi Z, Sinn E, Reddy VP (2005) Gadolinium triflate immobilized in imidazolium based ionic liquids: a recyclable catalyst and green solvent for acetylation of alcohols and amines. Green Chem 7:203-206. https://doi. org/10.1039/B416359A

16. Kamal A, Khan MNA, Reddy KS, Srikanth YVV, Krishnaji T (2007) $\mathrm{Al}(\mathrm{OTf})_{3}$ as a highly efficient catalyst for the rapid acetylation of alcohols, phenols and thiophenols under solvent-free conditions. Tetrahedron Lett 48:3813-3818. https://doi.org/10.1016/j. tetlet.2007.03.162

17. Chandrasekhar S, Ramchander T, Takhi M (1998) Acylation of alcohols with acetic anhydride catalyzed by $\mathrm{TaCl}_{5}$ : Some implications in kinetic resolution. Tetrahedron Lett 39:3263-3266. https ://doi.org/10.1016/S0040-4039(98)00465-1

18. Chakraborti AK, Gulhane R (2003) Indium(III) chloride as a new, highly efficient, and versatile catalyst for acylation of phenols, thiols, alcohols, and amines. Tetrahedron Lett 44:6749-6753. https://doi.org/10.1016/S0040-4039(03)01641-1

19. Ghosh R, Maiti S, Chakraborti A (2005) Facile catalyzed acylation of alcohols, phenols, amines and thiols based on $\mathrm{ZrOCl}_{2} \cdot 8 \mathrm{H}_{2} \mathrm{O}$ and acetyl chloride in solution and in solvent-free conditions. Tetrahedron Lett 46:147-151. https://doi.org/10.1016/j.tetle t.2004.10.164

20. Firouzabadi H, Iranpoor N, Nowrouzi F, Amani K (2003) Aluminium dodecatungstophosphate (AIPW ${ }_{12} \mathrm{O}_{40}$ ) as a highly efficient catalyst for the selective acetylation of $-\mathrm{OH},-\mathrm{SH}$ and $-\mathrm{NH}_{2}$ functional groups in the absence of solvent at room temperature. Chem Commun. https://doi.org/10.1039/B300775H

21. Chakraborti AK, Shivani R (2006) Magnesium Bistrifluoromethanesulfonimide as a New and Efficient Acylation Catalyst. J Org Chem 71:5785-5788. https://doi.org/10.1021/jo0605142

22. Joseph JK, Jain SL, Sain B (2007) Alumina supported $\mathrm{MoO}_{3}$ as a highly efficient and recyclable heterogeneous catalyst for the chemoselective acetylation of alcohols, phenols amines and thiols with acetic anhydride under solvent free conditions. J Mol Catal A: Chem 267:108-111. https://doi.org/10.1016/j. molcata.2006.11.026

23. Farhadi S, Zaidi M (2009) Bismuth ferrite $\left(\mathrm{BiFeO}_{3}\right)$ nanopowder prepared by sucrose-assisted combustion method: $A$ novel and reusable heterogeneous catalyst for acetylation of amines, alcohols and phenols under solvent-free conditions. J Mol Catal A: Chem 299:18-25. https://doi.org/10.1016/j.molca ta.2008.10.013

24. Shimizu K, Higuchi T, Takasugi E, Hatamachi T, Kodama T, Satuma A (2008) Characterization of Lewis acidity of cation-exchanged montmorillonite K-10 clay as effective heterogeneous catalyst for acetylation of alcohol. J Mol Catal A: Chem 284:89-96. https ://doi.org/10.1016/j.molcata.2008.01.013

25. Rana S, Mallick S, Rath D, Parida KM (2012) Characterization of novel $\mathrm{Cs}$ and $\mathrm{K}$ substituted phosphotungstic acid modified MCM-41 catalyst and its catalytic activity towards acetylation of aromatic alcohols. J Chem Sci 124:1117-1125. https://doi. org/10.1007/s12039-012-0291-8

26. Jin TS, Ma YR, Zhang ZH, Li TS (1998) Sulfamic acid catalysed acetylation of alcohols and phenols with acetic anhydride. Synth Commun 28:3173-3177. https://doi.org/10.1080/0039791980 8004417

27. Das B, Thirupathi P (2007) A highly selective and efficient acetylation of alcohols and amines with acetic anhydride using $\mathrm{NaHSO}_{4} \cdot \mathrm{SiO}_{2}$ as a heterogeneous catalyst. J Mol Catal A: Chem 269:12-16. https://doi.org/10.1016/j.molcata.2006.12.029 
28. Rajabi F (2009) A heterogeneous cobalt (II) Salen complex as an efficient and reusable catalyst for acetylation of alcohols and phenols. Tetrahedron Lett 50:395-397. https://doi.org/10.1016/j. tetlet.2008.11.024

29. Wang W, Cheng W, Shao L, Yang J (2008) [TMBSA] $\left[\mathrm{HSO}_{4}\right]$ lonic Liquid as Novel Catalyst for the Rapid Acetylation of Alcohols, Hydroxyesters and Phenols under Solvent-free Conditions. Catal Lett 121:77-80. https://doi.org/10.1007/s10562-007-9295-2

30. Chemat F, Rombaut N, Meullemiestre A, Turk M, Perino S, Fabiano-Tixier AS, Abert-Vian M (2017) Review of green food processing techniques. Preservation, transformation, and extraction. Innov Food Sci Emerg Technol 41:357-377. https://doi. org/10.1016/j.ifset.2017.04.016

31. Anastas P, Eghbali N (2010) Green chemistry: principles and practice. Chem Soc Rev 39:301-312. https://doi.org/10.1039/ b918763b

32. Sun R, Tomkinson J, Mao FC, Sun XF (2001) Physicochemical characterization of lignins from rice straw by hydrogen peroxide treatment. J Appl Polym Sci 79:719-732. https://doi. org/10.1002/1097-4628(20010124)79

33. Salunkhe DK, Kadam SS, Chavan JK (1985) Postharvest biotechnology of food legumes. Chem Compos 1985:29-52

34. Girish TK, Pratape VM, Prasad Rao UJS (2012) Nutrient distribution, phenolic acid composition, antioxidant and alpha-glucosidase inhibitory potentials of black gram (Vigna mungo L.) and its milled by-products. Food Res Int 46:370-377. https://doi. org/10.1016/j.foodres.2011.12.026

35. Sun RC, Tomkinson J, Ma PL, Liang SF (2000) Comparative study of hemicelluloses from rice straw by alkali and hydrogen peroxide treatments. Carbohydr Polym 42:111-122. https://doi. org/10.1016/S0144-8617(99)00136-8

36. Ishikura N, Iwata M, Miyazaki S (1981) Flavonoids of some Vigna-plants in leguminosae. J Plant Res 94:197-205. https:// doi.org/10.1007/BF02488610

37. Lee MR, Chen CM, Hwang BH, Hsu LM (1999) Analysis of saponins from black bean by electrospray ionization and fast atom bombardment tandem mass spectrometry. J Mass Spectrom 34:804-812. https://doi.org/10.1002/(SICI)1096-9888(199908)34
38. Das R, Chakraborty D (2011) Silver triflate catalyzed acetylation of alcohols, thiols, and amines. Synthesis 10:1621-1625. https ://doi.org/10.1055/s-0030-1259999

39. Chakraborti AK, Gulhane R (2003) Perchloric acid adsorbed on silica gel as a new, highly efficient, and versatile catalyst for acetylation of phenols, thiols, alcohols, and amines. Chem Commun. https://doi.org/10.1039/B304178F

40. Chikkulapalli A, Aavula SK, Sumathi MSGS (2015) Convenient $\mathrm{N}$-acetylation of amines in $\mathrm{N}, \mathrm{N}$-dimethylacetamide with $\mathrm{N}$, $\mathrm{N}$-carbonyldiimidazole. Tetrahedron Lett 56:3799-3803. https ://doi.org/10.1016/j.tetlet.2015.04.077

41. Brahmachari G, Laskar S, Sarkar S (2010) A Green approach to chemoselective $\mathrm{N}$-acetylation of amines using catalytic amount of Zinc Acetate in acetic acid under microwave irradiation. Indian J Chem 49:1274-1281. https://doi.org/10.1002/ chin.201103066

42. Seddighi M, Shirini F, Jolodar OG (2016) Preparation, characterization and application of $\mathrm{RHA} / \mathrm{TiO}_{2}$ nanocomposites in the acetylation of alcohols, phenols and amines. C R Chim 19:10031010. https://doi.org/10.1016/j.crci.2016.03.004

43. Veisi H, Taherib S, Hemmatia S (2016) Preparation of polydopamine sulfamic acid-functionalized magnetic $\mathrm{Fe}_{3} \mathrm{O}_{4}$ nanoparticles with a core/shell nanostructure as heterogeneous and recyclable nanocatalysts for the acetylation of alcohols, phenols, amines and thiols under solvent-free conditions. Green Chem 18:6337-6348. https://doi.org/10.1039/C6GC01975G

44. Chavan SP, Anand R, Pasupathy K, Rao BS (2001) Catalytic acetylation of alcohols, phenols, thiols and amines with zeolite H-FER under solventless conditions. Green Chem 3:320-322. https:// doi.org/10.1039/B109093C

Publisher's Note Springer Nature remains neutral with regard to jurisdictional claims in published maps and institutional affiliations. 